\title{
Mechanisms underlying oocyte activation and postovulatory ageing
}

\author{
Rafael A. Fissore, Manabu Kurokawa, Jason Knott, \\ Mao Zhang and Jeremy Smyth \\ Department of Veterinary and Animal Sciences, University of Massachusetts, \\ Amherst, MA 01003, USA
}

\begin{abstract}
Mammalian oocytes undergo significant growth during oogenesis and experience extensive cytoplasmic and nuclear modifications immediately before ovulation in a process commonly referred to as oocyte maturation. These changes are intended to maximize the developmental success after fertilization. Entry of a spermatozoon into the oocyte, which occurs a few hours after ovulation, initiates long-lasting oscillations in the free intracellular calcium $\left(\left[\mathrm{Ca}^{2+}\right]_{\mathrm{i}}\right)$ that are responsible for all events of oocyte activation and the initiation of the developmental programme that often culminates in the birth of young. Nevertheless, the cellular and molecular changes that occur during maturation to optimize development are transient, and exhibit rapid deterioration. Moreover, fertilization of oocytes after an extended residence in the oviduct (or in culture) initiates a different developmental programme, one that is characterized by fragmentation, programmed cell death, and abnormal development. Inasmuch as $\left[\mathrm{Ca}^{2+}\right]_{i}$ oscillations can trigger both developmental programmes in mammalian oocytes, this review addresses one of the mechanism(s) possibly used by spermatozoa to initiate these persistent $\left[\mathrm{Ca}^{2+}\right]_{\mathrm{i}}$ responses, and the cellular and molecular changes that may underlie the postovulatory cellular fragmentation of ageing mammalian oocytes.
\end{abstract}

Mammalian oocytes acquire the ability to be fertilized and to give rise to viable embryos in waves of growth and maturation. This process commences approximately at the time of puberty and continues for a significant portion of the lifespan of females of most mammalian species. While arrested at the diplotene stage of the first meiosis, also commonly referred to as the germinal vesicle (GV) stage, follicle-enclosed oocytes grow to their maximal size. During this time, oocytes accumulate significant amounts of mRNAs and proteins that will be used later during maturation, fertilization and zygote development. After the completion of oocyte growth, the follicle continues to grow until it reaches ovulatory size. It is at this time that an $\mathrm{LH}$ surge induces the release of a metaphase II (MII)-arrested oocyte into the oviduct, concluding the ovarian life of the oocyte. The transition from the GV stage to MII immediately preceding ovulation is referred to as 'oocyte maturation' and entails a complex sequence of nuclear and cytoplasmic events that prepares the oocyte for fertilization and initiation of development.

Although the time required to complete oocyte growth and maturation is measured in weeks or months, the fertilizable lifespan of mammalian oocytes is remarkably short, less than $10 \mathrm{~h}$. Fertilization within this narrow

Email: rfissore@vasci.umass.edu window of developmental opportunity results in oocyte activation and normal embryonic development. Oocyte activation is a process in which the fertilizing spermatozoon initiates repetitive increases in the free intracellular calcium concentration $\left(\left[\mathrm{Ca}^{2+}\right]_{i}\right)$. These $\left[\mathrm{Ca}^{2+}\right]_{i}$ oscillations signal all events of activation including release of cortical granules and prevention of polyspermy, resumption and completion of meiosis, and pronuclear formation and subsequent mitotic cleavages (reviewed by Schultz and Kopf, 1995). In contrast, oocytes that are fertilized after this optimal period, when oocyte 'ageing' sets in, exhibit severely compromised developmental success that often culminates in fragmentation of blastomeres and embryonic death (Marston and Chang, 1964 and references therein). $\left[\mathrm{Ca}^{2+}\right]_{i}$ oscillations induce both developmental outcomes (Gordo et al., 2000a); therefore, this review will summarize information describing the optimization of $\mathrm{Ca}^{2+}$ release mechanism(s) of oocytes during maturation, how the spermatozoa might initiate oscillations, and the cellular and molecular events that may underlie postovulatory oocyte ageing.

\section{Oocyte maturation: preparation for fertilization}

Oocyte maturation in most mammalian species is completed within 12-24 $\mathrm{h}$, and during this brief period significant qualitative changes in protein synthesis take 
place that are intended to initiate and regulate resumption of meiosis, prevent polyspermic fertilization, and promote exit from the MII arrest (reviewed by Wassarman and Albertini, 1994); in other words, these changes make oocytes 'activation competent'. Re-initiation of meiosis is made possible by the activation of maturation-promoting factor (MPF), which comprises the products of the p34 cdc2 and cyclin genes (Draetta and Beach, 1988). The activation of MPF is responsible for inducing germinal vesicle breakdown and promoting progression into meiosis II (Dekel, 1996). In addition to MPF, activation of mitogen-activated protein kinase (MAPK) plays a role in regulating the transition from meiosis I to meiosis II and, more importantly, in the MII stage arrest (reviewed by Ferrel, 1999). These kinases, mostly in conjunction with other kinases or phosphatases, may also regulate the completion of 'cytoplasmic maturation' that occurs before ovulation.

One of the cytoplasmic functions that is modified during maturation is the ability to release $\mathrm{Ca}^{2+}$ (reviewed by Carroll et al., 1996). Sperm-induced $\left[\mathrm{Ca}^{2+}\right]_{i}$ oscillations are the hallmark of mammalian fertilization and although the mechanism(s) used by the spermatozoon to initiate these oscillations is still under investigation, it has become apparent that the inositol 1,4,5-trisphosphate receptor isoform-1 (IP $R-1)$ is the channel of choice during fertilization (Miyazaki et al., 1993). In support of this, the sensitivity of $\mathrm{IP}_{3} \mathrm{R}-1$, as evidenced by enhanced $\mathrm{Ca}^{2+}$ responses to stimulation with $\mathrm{IP}_{3}$, increases gradually during maturation from the GV stage and peaks at MII (Fujiwara et al., 1993; Mehlmann and Kline, 1994; He et al., 1997). Fertilization of oocytes at different stages of maturation induces oscillations only in oocytes that have nearly completed maturation (Fujiwara et al., 1993; Jones et al., 1995), indicating that a maximally sensitized $I P_{3} R$ system is required for the initiation of oscillations in mammalian oocytes.

Several molecular mechanisms may account for the heightened sensitivity of the $I P_{3} R-1$ at MII. First, a noticeable, albeit not overwhelming, increase in the density of these receptors has been observed during maturation in oocytes of mammalian and non-mammalian species (Mehlmann et al., 1996; He et al., 1997; Kume et al., 1997). Second, the phosphorylation status of the receptor may change during maturation, resulting in enhanced conductivity of the receptor. The $I_{3} R-1$ has multiple phosphorylation consensus sequences and phosphorylation of selected sites affects the conductivity of the channel (Patel et al., 1999), although the phosphorylation status of the $\mathrm{IP}_{3} \mathrm{R}-1$ in mammalian oocytes and zygotes has not been investigated. In addition, $\mathrm{IP}_{3}$ Rs form complexes with other proteins and this, in turn, may also alter the conductivity of the channel (Bultynck et al, 1999). Other changes that may augment $\mathrm{IP}_{3} \mathrm{R}$-1-mediated $\mathrm{Ca}^{2+}$ release during maturation include increased $\mathrm{Ca}^{2+}$ store content and redistribution of the endoplasmic reticulum (ER) (Jones et al., 1995; Shiraishi et al., 1995). Therefore, several changes that occur concomitantly during oocyte maturation are intended to maximize $\mathrm{Ca}^{2+}$ release at the time of fertilization, underscoring the significance of this signalling event not only for exit of meiosis, but also for increased developmental success of early embryos. On the other hand, prolonged residence in the oviduct without fertilization results in gradual inactivation of the $\mathrm{Ca}^{2+}$ release mechanisms, and this may be responsible, at least in part, for the fragmentation and poor developmental success of zygotes that result from delayed fertilization.

\section{Oocyte activation: signalling mechanism for sperm- induced $\left[\mathrm{Ca}^{2+}\right]_{i}$ oscillations}

The signalling mechanism used by the spermatozoa to initiate and maintain $\left[\mathrm{Ca}^{2+}\right]_{i}$ oscillations has not been elucidated, although several hypotheses have been proposed (Schultz and Kopf, 1995; Stricker, 1999); the evidence for and against each hypothesis has been reviewed recently and therefore will not be discussed here (Swann and Lai, 1997; Swann et al., 2001). Instead, the focus will be on some of the less thoroughly reviewed aspects of the 'Fusion/Sperm Factor (SF)' hypothesis. This hypothesis proposes that a factor from the spermatozoon initiates $\left[\mathrm{Ca}^{2+}\right]_{\mathrm{i}}$ oscillations when delivered into the ooplasm upon fusion of the gamete membranes. The strongest experimental evidence in support of this hypothesis emanates from the ability of spermatozoa to initiate $\left[\mathrm{Ca}^{2+}\right]_{\text {i }}$ oscillations, when injected directly into the ooplasm, despite bypassing the presumably required interactions of the gamete membranes (Tesarik et al., 1994; Nakano et al., 1997). Likewise, the demonstrated ability of sperm fraction or factor preparations to initiate $\mathrm{Ca}^{2+}$ release when they are injected into oocytes of several mammalian species provides additional support for this hypothesis (Wu et al., 1997; Swann et al., 2001). Nevertheless, the lack of success in the isolation and characterization of the sperm active molecule(s) has delayed progress. The following discussion will focus on some of the outstanding issues such as the number of active SF molecules, the location of SF, and the regulation of its release.

\section{How many sperm factors?}

Injection of SFs into mammalian oocytes can initiate, and in many cases replicate, the $\mathrm{Ca}^{2+}$ responses induced by fertilization. In most studies the injected SFs were obtained after sonication of spermatozoa or after cycles of freezing and thawing, and the processed supernatants were denominated soluble or cytosolic SFs, since these lysis procedures are generally expected to release most of the cytosolic components of the cell. However, given the special configuration of sperm cells and their lack of obvious cytoplasm, it is presently unknown which of the sperm domains contribute proteins to these soluble fractions. Moreover, it has become readily apparent that the soluble sperm proteins are not the only fractions able to trigger $\mathrm{Ca}^{2+}$ release. Results from experiments using the intracytoplasmic sperm injection (ICSI) technique, which makes 
possible the injection of whole spermatozoa into oocytes, showed that injection of demembranated sperm heads, which are consequently devoid of soluble SFs, is still able to induce $\mathrm{Ca}^{2+}$ release (Perry et al., 2000). These results were interpreted to mean that the spermatozoa may be equipped with more than one SF, and that the soluble SF may not be involved in the persistence of oscillations during fertilization as these fractions are likely to be lost before gamete fusion. This interpretation may be premature for several reasons. First, the protein compositions of the soluble and the less soluble SFs have not been compared extensively. Second, these experiments were carried out exclusively using mouse spermatozoa that are known to contain lower soluble $\mathrm{Ca}^{2+}$ activity than spermatozoa from hamsters or pigs (Swann et al., 2001; M. Kurokawa, H. Wu and R. A. Fissore, unpublished), which have been used mainly for the preparation of soluble SFs. Remarkably, our unpublished chromatographic fractionation studies of soluble and less soluble (Triton X-resistant) pig SFs using Superose 12 and hydroxyapatite columns reveal that the $\mathrm{Ca}^{2+}$ active molecules from both SFs exhibit very similar elution profiles in both columns, indicating that the same $\mathrm{Ca}^{2+}$ active molecule(s) may be present in both soluble and less soluble fractions. Whether the putative molecule has diverse locations in the spermatozoon, or may be associated with different proteins that in turn regulate or modify its release remains to be elucidated.

\section{Where is the sperm factor(s)?}

Although the results obtained using sperm heads demembranated with Triton X-100 underscored the possible functional significance of the detergent-resistant SF fraction, they do not reveal the sperm structure(s) that harbours the $\mathrm{Ca}^{2+}$-active molecule. However, these studies indicate that the theca, the sperm perinuclear material, is the structure most likely to carry the $\mathrm{Ca}^{2+}$-releasing molecule(s). This interpretation is based on the finding that after Triton X-100 treatment, the theca is the only structure that remains associated with the sperm nucleus (Kimura et al., 1998; Perry et al., 1999). In support of this notion, removal of the sperm theca using SDS and trypsin was shown to eliminate the ability of mouse sperm heads to activate oocytes after ICSI (Kimura et al., 1998). Nonetheless, several questions cannot be resolved by the experimental approach just described. First, a significant amount of soluble SF is released during treatment with Triton X-100, and the location of such SF cannot be determined. Second, whether or not the theca-associated $\mathrm{Ca}^{2+}$ activity is removed, or simply inactivated, by the trypsin and SDS treatments was not ascertained because the $\mathrm{Ca}^{2+}$ activity was never recovered after the treatments. Finally, it remains to be demonstrated whether the theca may serve as an anchor from which the release of the factor takes place, or whether the active molecule(s) of the SF is an integral component of the theca. These questions are easily testable and the answers should contribute to the elucidation of the location of the SFs in the spermatozoa as well as the mode of release of the factor.

\section{Mode of release of sperm factor}

How the $\mathrm{Ca}^{2+}$-active component of the spermatozoon is released and the oocyte conditions that promote or regulate the release are presently not known. For instance, is the factor gradually released or, alternatively, does it move away from the sperm nucleus soon after fusion? Evidence in support of the latter possibility is provided by the finding that soon after entry of the spermatozoon into the oocyte, the increase in $\left[\mathrm{Ca}^{2+}\right]_{i}$ appears to originate away from location of entry of the spermatozoon and opposite to the animal pole (Kline et al., 1999; Deguchi et al., 2000). Likewise, the demonstration that fusion of a cytoplast from a telophase-stage fertilized mouse oocyte to an unfertilized oocyte can induce activation indicates that the factor has a cytoplasmic location, although $\left[\mathrm{Ca}^{2+}\right]_{i}$ Oscillations were not measured in this study (Ogonuki et al., 2001). As suggestive as these studies are of an early cytosolic location of the factor, it is plausible that a fraction of the factor remains associated with the sperm nucleus several hours after sperm entry. What is more, it is possible that the Triton X-100-resistant SF fraction remains associated with the nucleus for several hours, and is responsible for the long duration of the oscillations, especially in large domestic species in which oscillations are known to last in excess of 10 h (Fig. 1). Nevertheless, despite these appealing models of release, basic functional and molecular evidence is needed to elucidate the regulation of release of the factor.

Although the fate of the $\mathrm{Ca}^{2+}$-active molecule of the spermatozoon within the first few hours after fusion is presently unknown, it appears that by the time of pronuclear formation, at least a portion of it is associated with the pronuclear structures. Early studies of mouse zygotes by Kono et al. (1995) reported that transfer of male or female pronuclei into MII oocytes was able to reinitiate oscillations, whereas fusion of comparably sized cytoplasts was unable to do so. Notably, studies involving injection of physiological amounts of pig SF into mouse oocytes showed that although these fractions can initiate oscillations efficiently, they are not as proficient at associating with the pronuclei. For example, in oocytes fertilized by ICSI, pronuclear envelope breakdown, either spontaneous or induced by exposure to okadaic acid, was accompanied by an increase in $\left[\mathrm{Ca}^{2+}\right]_{\mathrm{i}}$, whereas SF-generated zygotes failed to show such a response (Gordo et al., 2002a). In addition, oscillations ceased earlier in these oocytes compared with those fertilized normally, even when meiotic exit was inhibited by the addition of colcemid (Gordo et al., 2002a). Thus, the association of the $\mathrm{Ca}^{2+}$-active molecule of spermatozoa with pronuclear structures may reflect the presence of an intact SF molecule(s), or SF molecules associated with the correct partners. Such an association of SF with pronuclear binding partners may affect the stability of the factor. Elucidation of the domain(s) or molecules that mediate the association or targetting of SF would be of interest. 


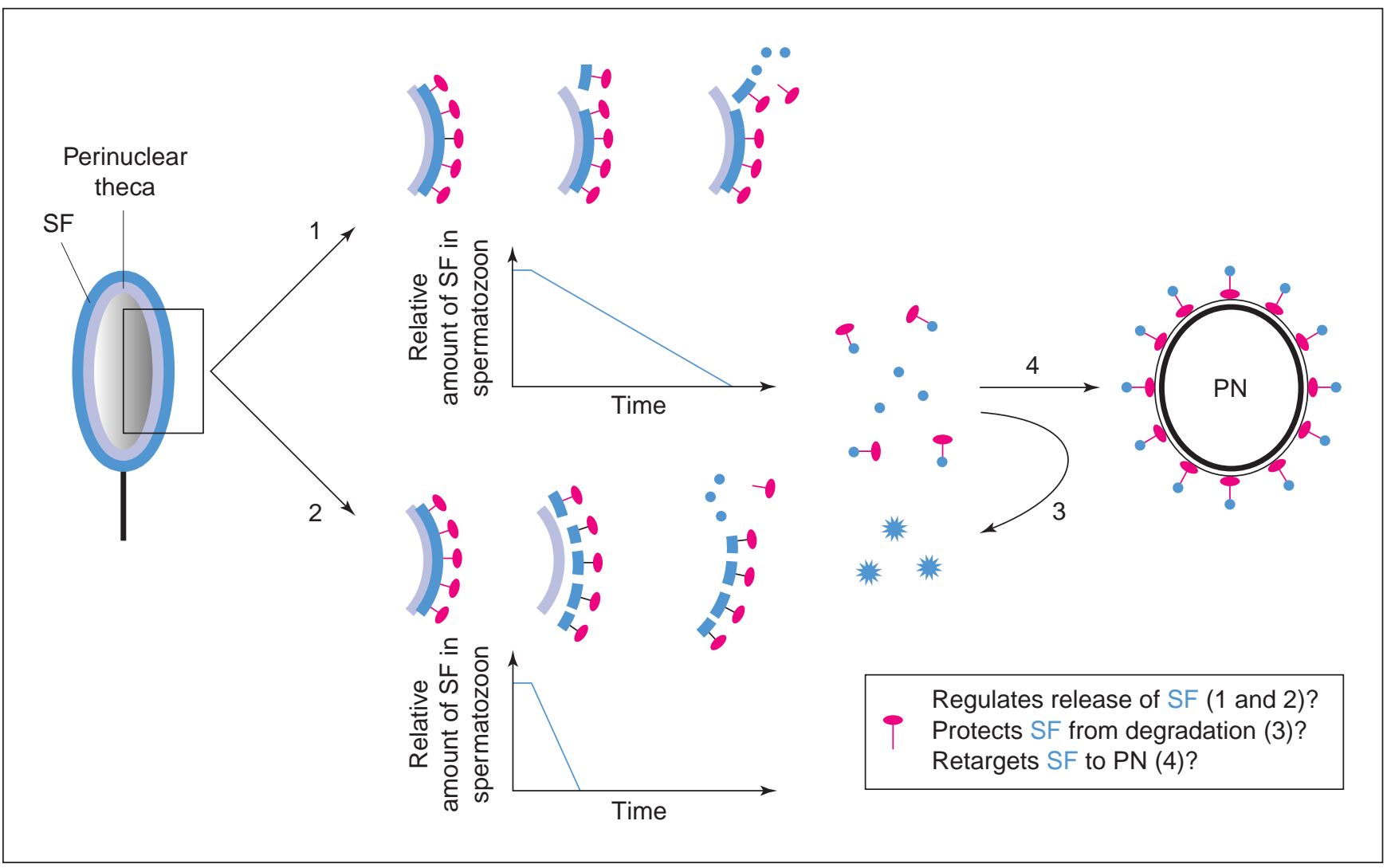

Fig. 1. Models for release of the $\mathrm{Ca}^{2+}$ active factor from the spermatozoon during fertilization in mammalian oocytes. Two models are shown: (1) the release of the factor from the sperm head is gradual; (2) the factor becomes dissociated from the sperm head within the first hour after fertilization. The symbols in blue denote sperm factor (SF), the $\mathrm{Ca}^{2+}$-active molecule(s) of spermatozoa. The symbols in red denote a domain or accessory protein, which may be important in regulating the release of the factor from the spermatozoon, or its stability after release, or its targeting to the pronuclear (PN) envelope area. The supposition for the need of a correctly exposed domain or accessory protein to control some of the functions of SF arises from the findings that the oscillations induced by injections of SF into mammalian oocytes seem to exhibit shorter duration than those initiated by the spermatozoa.

It is important to note that notwithstanding the success of ICSI in several mammalian species, its effectiveness is far from acceptable in large domestic species (Horiuchi and Numabe, 1999; Suttner et al., 2000). The most important limitation appears to be an inability of injected spermatozoa to deliver an appropriate activation stimulus in the oocytes of these species. Therefore, although the Fusion/SF hypothesis may represent the mechanism responsible for oscillations in mammalian species, we are far from understanding fundamental aspects of its mode of release, location and activation, and must contemplate the possibility of significant species-specific variability in mammals.

\section{Postovulatory oocyte ageing: a prelude to fragmentation and cell death}

Oocyte maturation is timed in such a manner that sperm entry, activation and developmental competence are maximal within a few hours after ovulation; in mice nearly
$100 \%$ of oocytes are expected to be fertilized within $6 \mathrm{~h}$ of ovulation (Braden and Austin, 1954). Nonetheless, interference with this timing is now occurring with increased frequency, especially in species in which humans intervene to control the number of ovulations or the genetic makeup of the progeny. The end-result is fertilization of 'aged oocytes'. Zygotes from aged oocytes reportedly show limited developmental success and undergo programmed cell death or apoptosis. Apoptosis, a process of cell selection present in all organisms, mediates the elimination of damaged cells and the strict selection, and consequent attrition, of germ cells that takes place in the gonads before and after birth (reviewed by Dunkel et al., 1997; Morita and Tilly, 1999). The molecules involved in programmed cell death have been extensively reviewed elsewhere (Adams and Cory, 1998; Thornberry and Lazebnik, 1998; Heiden and Thompson, 1999); therefore, we will focus on new evidence involving mechanisms that may underlie apoptosis or fragmentation that ensues after fertilization or activation of ovulated, aged mammalian oocytes. 


\section{Fertilization or activation induces a different developmental outcome in aged oocytes}

The negative impact of delayed fertilization on reproductive success has been known for several decades, but the stage(s) at which embryonic development is compromised, and the mechanism(s) responsible for the developmental failure, were not apparent from earlier studies. Marston and Chang (1964) noted that postovulatory ageing, in mice, hindered embryo development soon after fertilization as they observed that within $24 \mathrm{~h}$ after fertilization, grossly mis-shapen and fragmented zygotes developed when insemination was delayed for more than $12 \mathrm{~h}$ after ovulation. Subsequent studies in mice confirmed (Juetten and Bavister, 1983) and extended these findings by showing that aged oocytes exhibit abnormal morphological characteristics before fertilization, such as the disappearance of the microfilament-rich area over the meiotic spindle, disruption of and abnormal spindle location, and chromatin disorganization (Webb et al., 1986). These changes appear to be the consequence of decreasing MPF and MAPK activities, and seem to develop faster in the oviduct than in vitro (Xu et al., 1997; Abbott et al., 1998). This progressive deterioration leads to oocyte fragmentation even in the absence of fertilization (Takase et al., 1995; Fujino et al., 1996; Tarin et al., 2001). Both spontaneous and fertilization-induced fragmentation may have a genetic component since they appear, at least in mice, to be influenced by the strain(s) under investigation (Warner, et al., 1998; Hawes et al., 2001).

As our understanding of oocyte ageing and its developmental consequences have gradually progressed, insights into the mechanism and role of apoptosis have been revealed in several cellular paradigms. Of particular relevance was the demonstration that the postnatal decline in the female germ cell population is mediated by apoptosis (De Pol et al., 1997; Tilly, 2001). Nevertheless, the molecular mechanism responsible for postovulatory fragmentation of oocytes was not ascertained until Takase et al. (1995) showed that ovulated unfertilized mouse oocytes cultured for extended periods undergo cytoplasmic fragmentation accompanied by DNA fragmentation, as determined by terminal deoxynucleotidyl transferase (TdT) nick-end labelling (TUNEL), both of which are classical signs of programmed cell death. Since then, several studies have extended those results by showing that apoptosis is not only observed after fertilization of aged oocytes, or of oocytes from ageing females, but also after exposure of newly ovulated mouse oocytes to chemical or chemotherapeutic compounds (Weil et al., 1996; Perez et al., 1997, 1999a).

Apoptosis requires the expression and activation of specific genes involved in the execution of the cell suicide programme. For the purpose of this review, suffice it to say that mouse oocytes express most of the genes known to participate in this programme (Jurisicova et al. 1998; Exley et al., 1999; Rucker et al., 2000). Mouse oocytes express several caspases, which are proteases responsible for the dismantling of cells, and several of the anti- and proapoptotic members of the $\mathrm{BCl}-2$ gene family. Pro-apoptotic family members promote the release of cytochrome $c$, a component of the mitochondrial respiratory chain that induces the activation of caspases when released into the cytosol, whereas anti-apoptotic members block the release of this factor (Adams and Cory, 1998). Results from gene disruption and overexpression studies in the ovary underscore the importance of these molecules in oocyte cell death. Oocytes from mice lacking caspase 2 or Bax, or overexpressing $\mathrm{BCl}-2$, are resistant to apoptosis induced by exposure to chemotherapeutic agents or that occurs spontaneously after ovulation (Bergeron et al., 1998; Morita et al., 1999; Perez et al., 1999b). Hence, as proposed for somatic cells (Oltvai et al., 1993), alterations in the amounts or ratios of the protein products of these genes may underlie fragmentation and cell death in aged oocytes too.

\section{Mitochondrial dysfunction in aged oocytes}

Mitochondrial dysfunction is likely to play an important role in the predisposition of aged oocytes to spontaneous and fertilization- or activation-induced fragmentation. Mitochondria harbour important anti-apoptotic as well as apoptogenic compounds, and serve as the bioenergetic centre of the cell by generating ATP (Green and Reed, 1998; Wang, 2001). Therefore, disruption of any of the mitochondrial membranes, or of its ability to generate ATP, is likely to have negative consequences on cell proliferation and survival. With respect to the latter, the ATP content of mouse oocytes appears to decrease steadily with time of culture (Chi et al., 1988), and in human oocytes, there may be a close association between developmental competence and intra-oocyte concentrations of ATP (Van Blerkom et al., 1995). Extended culture times also decrease the mitochondrial membrane potential in human oocytes (Wilding et al., 2001), possibly resulting in swelling of the mitochondrial matrix. In somatic cells, mitochondrial swelling precedes the rupture of the outer mitochondrial membrane, making possible the release of cytochrome $c$ and other apoptogenic products (Wang, 2001). Advanced stages of mitochondrial dysfunction are also associated with accumulation of reactive oxygen species, which further compromise cell survival. Importantly, exposure of oocytes to different concentrations of hydrogen peroxide was shown to induce release of cytochrome $c$ and to lower the mitochondrial membrane potential (Liu et al., 2000). Moreover, addition of dithiothreitol, a reducing agent, to the culture medium prevented some of the detrimental effects of oocyte ageing on fertilization and development (Tarin et al., 1998).

Results demonstrating that injection of purified mitochondria from somatic cells inhibits spontaneous postovulatory oocyte fragmentation in certain strains of mice (Perez et al., 2000) are consistent with the involvement of mitochondrial dysfunction in oocyte cell death. Likewise, 
the beneficial effects of 'cytoplasmic transfer', a process during which cytoplasm from fertile donor oocytes is injected into oocytes from females that have failed to conceive, reportedly to overcome some cases of human infertility, may by explained by the addition of fresh mitochondria during this procedure (Cohen et al., 1998). Nevertheless, the clinical application of these techniques should proceed with caution until studies are carried out to compare the developmental competence to term of these oocytes, and assess potential long-term detrimental effects of these procedures on the offspring.

\section{$\left[\mathrm{Ca}^{2+}\right]_{\mathrm{i}}$ oscillations and abnormal development in aged oocytes}

As previously mentioned, mammalian oocytes remain fully developmentally competent for a few hours after ovulation. In some cases, unfertilized aged oocytes undergo spontaneous fragmentation. However, in others, late fertilization results in the initiation of development, but high rates of fragmentation and apoptotic death are observed, and some of the surviving embryos appear to exhibit birth defects (Tarin et al., 1999). We have demonstrated that initiation of the $\left[\mathrm{Ca}^{2+}\right]_{\mathrm{i}}$ signal due to fertilization is capable of inducing fragmentation and activation of caspases in aged oocytes (Gordo et al., 2000), implying that this $\left[\mathrm{Ca}^{2+}\right]_{\mathrm{i}}$ signal may act as the instigator of apoptosis in aged oocytes. In addition, in human oocytes, caspase activity was detected only after fertilization, in fragments, and in embryos of poor morphology (Martinez et al., 2002).

A question that arises from these results is how can the same signal trigger such divergent developmental paths? Changes in $\mathrm{Ca}^{2+}$ homeostasis have been associated with cellular necrosis and programmed cell death, although the mechanism(s) by which $\left[\mathrm{Ca}^{2+}\right]_{i}$ changes induce apoptosis is not entirely clear (Trump and Berezesky, 1995; Berridge et al., 1998). Interestingly, $\mathrm{Ca}^{2+}$ responses in aged mouse oocytes are abnormal in several respects (Jones and Whittingham, 1996; Igarashi et al., 1997). For instance, the rate of increase of $\left[\mathrm{Ca}^{2+}\right]_{i}$ during fertilization or after stimulation by agonists is slower in aged oocytes. Likewise, the amplitude of the responses and the duration of the oscillations are decreased in these oocytes. Collectively, these results indicate altered $\mathrm{Ca}^{2+}$ homeostasis in aged oocytes (Takahashi et al., 2000). The molecular basis for this defective $\mathrm{Ca}^{2+}$ regulation has not been elucidated, but may involve the aforementioned decrease in ATP in conjunction with reduced $\mathrm{Bcl}-2$ expression in aged oocytes (Gordo et al., 2002b). Low availability of ATP may impair the function of the SERCA pumps, the $\mathrm{Ca}^{2+}$-ATPase pumps responsible for the refilling of the endoplasmic reticulum (ER). Reduced amounts of Bcl-2 may also negatively impact the function of the $\mathrm{Ca}^{2+}$ pump, although the role of $\mathrm{BCl}-2$ in $\mathrm{Ca}^{2+}$ homeostasis remains controversial (Diestelhorst and Dubyak, 1998; Pinton et al., 2000). Nonetheless, Kuo et al. (1998) suggest that Bcl-2 may upregulate the expression of SERCA mRNA and may interact directly with the pump, possibly modulating its function. Therefore, malfunction of the SERCA pump may be responsible for the abnormal $\mathrm{Ca}^{2+}$ homeostasis in aged oocytes.

Fertilization-associated $\left[\mathrm{Ca}^{2+}\right]_{i}$ oscillations may signal apoptosis in aged oocytes by inducing several cellular responses that simultaneously, and possibly synergistically, promote programmed cell death. First, the initiation of $\left[\mathrm{Ca}^{2+}\right]_{\mathrm{i}}$ oscillations may result in depletion of $\mathrm{Ca}^{2+}$ from the $E R$, as evidenced by the premature cessation of oscillations in aged oocytes. Low $\mathrm{Ca}^{2+}$ in the ER is an effective trigger of cell death in somatic cells (Jiang et al., 1994; Bian et al., 1997) and also suppresses protein synthesis (Soboloff and Berger, 2002), effects which are likely severely to limit embryo development. Second, there appears to be privileged communication between $\mathrm{IP}_{3} \mathrm{R}$-mediated $\mathrm{Ca}^{2+}$ release and mitochondrial function (Csordás et al., 1999; Szalai et al., 1999). The mitochondria serve as $\mathrm{Ca}^{2+}$ stores in the cell and have been shown to participate in the generation of oscillations in several types of cell, including mouse oocytes (Liu et al., 2001) and human embryos (Souza et al., 1997). Under optimal conditions, each of the $I P_{3} R$ mediated increases in $\left[\mathrm{Ca}^{2+}\right]_{i}$ stimulates mitochondrial function and ATP production. However, in the presence of a pro-apoptotic stimulus, $\mathrm{IP}_{3}$-mediated $\left[\mathrm{Ca}^{2+}\right]_{\mathrm{i}}$ oscillations signal the release of cytochrome $c$, a decrease in the mitochondrial membrane potential, and activation of caspases (Szalai et al., 1999). Therefore, we propose a model whereby postovulatory ageing of oocytes, which results in less ATP and $\mathrm{BCl}-2$ and an increase in hydrogen peroxide, act as a pro-apoptotic stimulus and, under these circumstances, fertilization-like $\left[\mathrm{Ca}^{2+}\right]_{\mathrm{i}}$ oscillations trigger cell death (Fig. 2).

$\left[\mathrm{Ca}^{2+}\right]_{i}$ oscillations are responsible for promoting progression of the cell cycle in mammalian oocytes and the apoptotic effects of $\mathrm{Ca}^{2+}$ release on aged oocytes may also rely, at least in part, on this transition. As mentioned, mammalian oocytes are arrested at MII, a stage that appears to confer resistance to apoptosis. For instance, mouse MII oocytes are susceptible to staurosporin-induced apoptosis, but at concentrations significantly higher than those required in somatic cells (Weil et al., 1996). Similarly, oocytes from Mos-null mice, which lack MAPK activity and fail to arrest at MII, progress into the cell cycle and undergo high rates of spontaneous fragmentation (Colledge et al., 1994). Aged oocytes also appear to be resistant to fragmentation by $\left[\mathrm{Ca}^{2+}\right]_{i}$ oscillations when arrested at MII. For example, the initiation of oscillations in aged oocytes treated with colcemid, which induces an arrest of the cell cycle at a mitosis-like stage without interfering with $\mathrm{Ca}^{2+}$ responses, failed to promote fragmentation, whereas similarly injected oocytes that were transferred into medium devoid of the drug fragmented shortly thereafter (Table 1). Similar fragmentation was observed in aged oocytes when progression of the cell cycle was promoted by exposure to ionomycin and 6-(dimethylamino)purine (DMAP), a common parthenogenetic activation combination (M. Zhang and R. A. Fissore, unpublished). Interestingly, Xenopus egg 


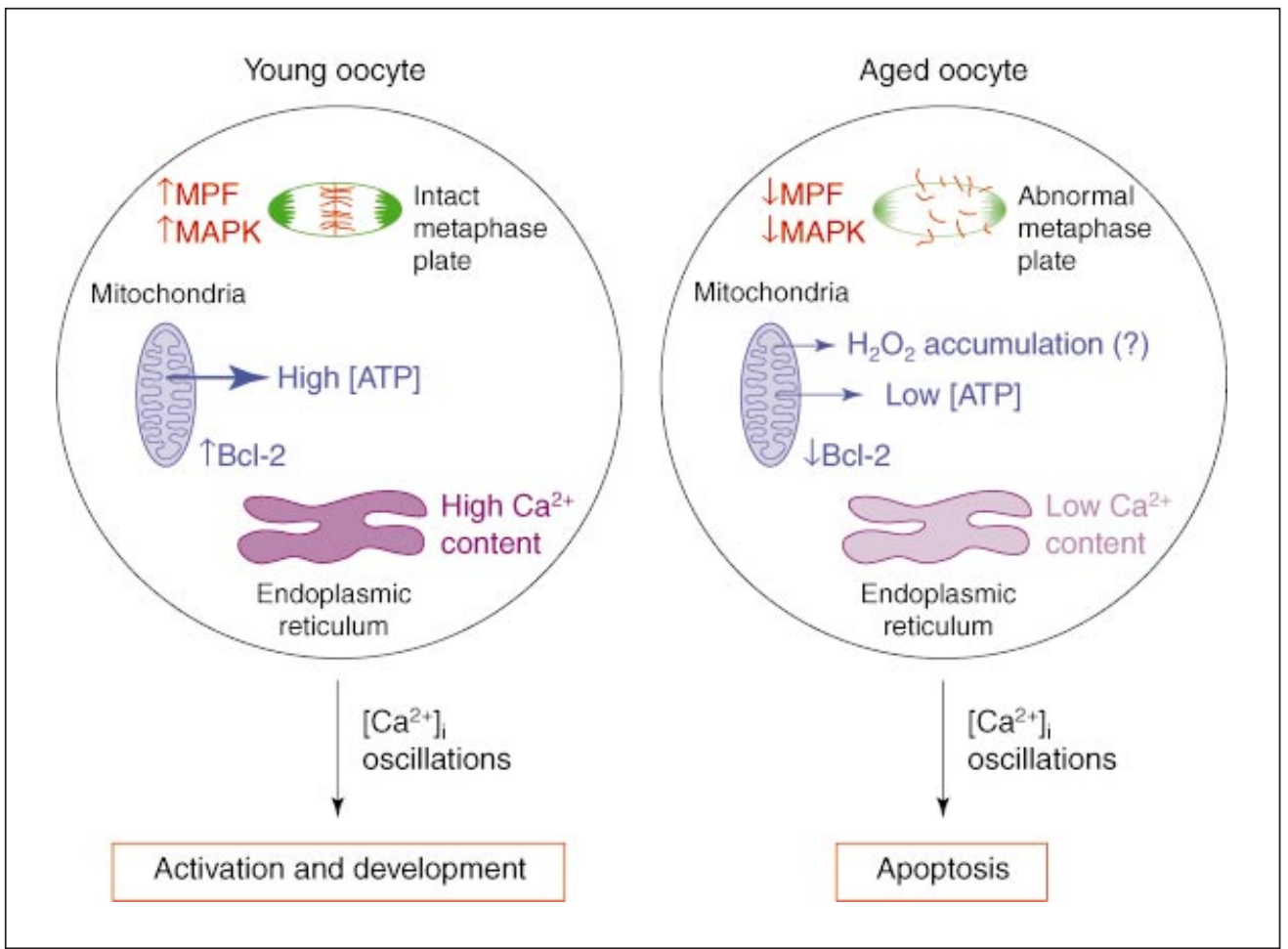

Fig. 2. Cellular and molecular changes in mammalian oocytes during ageing that may underlie fragmentation or developmental arrest after activation or fertilization. As oocytes age, a host of cellular functions may be compromised, which in turn compromise the ability of oocytes to initiate normal development. Aged eggs exhibit a steady decline of meiotic kinases, maturation-promoting factor (MPF) and mitogen-activated protein kinase (MAPK), and show decreased anti-apoptotic proteins and $\mathrm{Ca}^{2+}$ contents in the stores. Aged oocytes also appear to have a depressed mitochondrial function, which may result in the accumulation of reactive oxygen species as well as in the release of pro-apoptotic products after $\mathrm{Ca}^{2+}$ stimulation. Therefore, activation of aged oocytes may result in fragmentation or cell cycle arrest rather than in the customary normal initiation of development.

Table 1. Cell cycle arrest prevents $\left[\mathrm{Ca}^{2+}\right]_{\mathrm{i}}$ oscillation-induced fragmentation of aged mouse oocytes

\begin{tabular}{lccc}
\hline Treatment $^{\mathrm{a}}$ & Number of oocytes & Number of fragmented oocytes & Per cent age \\
\hline Colcemid $\left(0.1 \mu \mathrm{g} \mathrm{ml}^{-1}\right)$-culture & 15 & 1 & 6.6 \\
SF $\left(1 \mathrm{mg} \mathrm{ml}^{-1}\right.$-Culture & 16 & 10 & $62.5^{\mathrm{b} *}$ \\
SF-colcemid-culture & 21 & 2 & 9.5 \\
Colcemid-wash-SF-culture & 13 & 11 & $84.6^{*}$ \\
Colcemid-SF-colcemid-culture & 18 & 0 & 0 \\
\hline
\end{tabular}

a Oocytes were aged in potassium simplex optimized medium (KSOM) supplemented with colcemid for $24 \mathrm{~h}$. Colcemid-treated aged oocytes were injected with pig sperm factor (SF) to initiate $\mathrm{Ca}^{2+}$ responses. In one group (SF + colcemid), injections and injection after culture were conducted in the presence of colcemid. In the other two groups, injections were done in the absence of colcemid (wash), after which a group was cultured in colcemid-free conditions, whereas the other group of oocytes was returned to colcemid-containing culture conditions.

bexperiments were repeated twice.

*Significantly different from those within the column (chi-squared; $P<0.05$ ).

extracts are also significantly more resistant to apoptotic stimuli when prepared from MII-arrested eggs compared with those prepared from interphase stage eggs (Faure et al., 1997). Remarkably, when these extracts are maintained in the laboratory for a few hours, they appear spontaneously to initiate changes consistent with apoptosis, raising the possibility that 'extract ageing' also takes place (Smith et al., 2000).

It is possible that critical anti-apoptotic molecules are inactivated or degraded during ageing, and that progression of the cell cycle under these conditions promotes cell death. Toward this end, the decreasing concentrations of MPF and 
MAPK that occur during prolonged postovulatory ageing may favour the degradation of anti-apoptotic molecules. Interestingly, in somatic cells, reduced concentrations of MAPK and MPF favour degradation of Bcl-2 and other antiapoptotic proteins (Boucher et al., 2000; Breitschopf et al., 2000), whereas they do not seem to affect pro-apoptotic proteins (Wada et al., 1998). Remarkably, a similar regulation of anti-apoptotic proteins may occur in effect in oocytes, because reduced amounts of Bcl-2 mRNA and protein, but unchanged amounts of Bax mRNA, have been observed in aged mouse oocytes (Gordo et al., 2002b). In addition, in pig oocytes, fragmentation rates after activation seem to be directly associated with the amount of MPF (Kikuchi et al., 2000).

Progression of the cell cycle in aged oocytes may also promote fragmentation and death by activating apoptotic proteins the functions of which are regulated by phosphorylation. For instance, Bad, one of the pro-apoptotic members of the $\mathrm{Bcl}-2$ family of proteins, is primarily regulated by phosphorylation and its translocation to the ER occurs only in its dephosphorylated state. Calcineurin, a $\mathrm{Ca}^{2+}$-dependent phosphatase, dephosphorylates Bad (Wang et al., 1999), and translocated Bad promotes cell death by binding to and inactivating the anti-apoptotic members of the Bcl-2 family (Zha et al., 1996). Therefore, progression of the cell cycle and the consequent changes in the phosphorylation status of the oocyte may activate a molecule(s) such as Bad and, in aged mouse oocytes, which exhibit reduced amounts of anti-apoptotic proteins, fragmentation and cell death may ensue.

It is worth noting that molecular defects other than those outlined here may account for the fragmentation and developmental incompetence of fertilized aged oocytes. Nonetheless, abnormal $\mathrm{Ca}^{2+}$ homeostasis, decreased amounts of anti-apoptotic proteins, and exit of meiosis are likely to play an important role in limiting the developmental potential of aged oocytes.

\section{Conclusions}

The initiation of development at fertilization is a tightly controlled process that relies on the structural and molecular integrity of the oocyte and the fertilizing spermatozoon. Under optimal conditions, fertilization induces a series of $\left[\mathrm{Ca}^{2+}\right]_{i}$ oscillations that initiate radical alterations in the cellular and molecular organization of the oocyte that are critical for the progression of the embryonic programme. It follows that any changes in this structure that may compromise development, such as alterations induced by ageing, should signal an arrest of development. Oocytes have evolved an elaborate developmental checkpoint whereby the same $\mathrm{Ca}^{2+}$ signal is capable of promoting activation or apoptosis, depending on the cellular and molecular integrity of the oocyte. It is critical, therefore, that we further advance our understanding of the pathways that regulate $\mathrm{Ca}^{2+}$ release and the mechanisms by which it functions in divergent developmental pathways. Clarifica- tion of these pathways may have significant implications in improving the developmental outcome of embryos generated in vitro and in vivo in humans and animals of agricultural significance.

Supported in part by USDA grants (98-2359 and 99-2371).

\section{References}

Key references are identified by asterisks.

Abbott AL, Xu Z, Kopf GS, Ducibella T and Schultz RM (1998) In vitro culture retards spontaneous activation of cell cycle progression and cortical granule exocytosis that normally occur in in vivo unfertilized mouse eggs Biology of Reproduction 59 1515-1521

Adams JM and Cory S (1998) The Bcl-2 protein family: arbiters of cell survival Science 281 1322-1326

Bergeron L, Perez GI, Macdonald G et al. (1998) Defects in regulation of apoptosis in caspase-2-deficient mice Genes and Development 12 1304-1314

Berridge MJ, Bootman MD and Lipp P (1998) Calcium - a life and death signal Nature 395 645-648

Bian X, Hughes FM, Jr, Huang Y, Cidlowski JA and Putney JW, Jr (1997) Roles of cytoplasmic $\mathrm{Ca}^{2+}$ and intracellular $\mathrm{Ca}^{2+}$ stores in induction and suppression of apoptosis in S49 cells American Journal of Physiology 272 C1241-C1249

Boucher MJ, Morisset J, Vachon PH, Reed JC, Laine J and Rivard N (2000) MEK/ERK signaling pathway regulates the expression of $\mathrm{BCl}-2, \mathrm{BCl}-\mathrm{X}(\mathrm{L})$, and $\mathrm{Mcl}-1$ and promotes survival of human pancreatic cancer cells Journal of Cell Biochemistry 79 355-369

Braden AWH and Austin CR (1954) The fertile life of mouse and rat eggs Science 120 610-611

Breitschopf K, Haendeler J, Malchow P, Zeiher AM and Dimmeler S (2000) Post-translational modification of $\mathrm{BCl}-2$ facilitates its proteosomedependent degradation: molecular characterization of the involved pathway Molecular Cell Biology 20 1886-1896

Bultynck G, Missiaen L, Callewaert G, Parys JB and De Smedt H (1999) Do inositol 1,4,5-trisphosphate receptors function as multiprotein complexes Current Topics in Biochemical Research 1 193-204

Carroll J, Jones KT and Whittingham DG (1996) $\mathrm{Ca}^{2+}$ release and the development of $\mathrm{Ca}^{2+}$ release mechanisms during oocyte maturation: a prelude to fertilization Reviews of Reproduction 1 137-143

Chi MM, Manchester JK, Yang VC, Curato AD, Strickler RC and Lowry OH (1988) Contrast in the levels of metabolic enzymes in human and mouse ova Biology of Reproduction 39 295-307

Cohen J, Scott R, Alikani M, Schimmel T, Munne S, Levron J, Wu L, Brenner C, Warner C and Willadsen S (1998) Ooplasmic transfer in mature human oocytes Molecular Human Reproduction 4 269-280

Colledge WH, Carlton MBL, Udy GB and Evans MJ (1994) Disruption of Cmos causes parthenogenetic development of unfertilized mouse eggs Nature 370 65-68

Csordás G, Thomas AP and Hajnóczky G (1999) Quasi-synaptic calcium signal transmission between endoplasmic reticulum and mitochondria EMBO Journal 18 96-108

Deguchi R, Shirakawa H, Oda S, Mohri T and Miyazaki S (2000) Spatiotemporal analysis of $\mathrm{Ca}^{2+}$ waves in relation to the sperm entry site and animal-vegetal axis during $\mathrm{Ca}^{2+}$ oscillations in fertilized mouse eggs Developmental Biology 218 299-313

Dekel N (1996) Protein phosphorylation/dephosphorylation in the meiotic cell cycle of mammalian oocytes Reviews of Reproduction 1 82-88

De Pol A, Vaccina F, Forabosco A, Cavazzuti E and Marzona L (1997) Apoptosis of germ cells during human prenatal oogenesis Human Reproduction 12 2235-2241

Diestelhorst CW and Dubyak G (1998) Role of calcium in glucocorticosteroid-induced apoptosis of thymocytes and lymphoma cells: resurrection of old theories by new findings Blood 91 731-734

Draetta G and Beach D (1988) Activation of cdc2 protein kinase during mitosis in human cells: cell cycle-dependent phosphorylation and subunit rearrangement Cell 54 17-26 
Dunkel L, Hirvonen V and Erkkila K (1997) Clinical aspects of male germ cell apoptosis during testis development and spermatogenesis Cell Death and Differentiation 4 171-179

Exley GE, Tang C, McElhinny AS and Warner CM (1999) Expression of caspase and BCL-2 apoptotic family members in mouse preimplantation embryos Biology of Reproduction 61 231-239

Faure S, Vigneron S, Doree $\mathbf{M}$ and Morin N (1997) A member of the Ste20/pak family of protein kinases is involved in both arrest of Xenopus oocytes at G2/prophase of the first meiotic cell cycle and in the prevention of apoptosis $E M B O$ Journal 16 5550-5561

Ferrel JE, Jr (1999) Xenopus oocyte maturation: new lessons from a good egg BioEssays 21 833-842

Fujino Y, Ozaki K, Yamamasu S, Ito F, Matsuoka I, Hayashi E, Nakamura H, Ogita S, Sato E and Inoue M (1996) DNA fragmentation of oocytes in aged mice Human Reproduction 11 1480-1483

Fujiwara T, Nakada K, Shirakawa H and Miyazaki S (1993) Development of inositol trisphosphate-induced calcium release mechanism during maturation in hamster oocytes Developmental Biology 156 69-79

Gordo AC, Wu H, He CL and Fissore RA (2000a) Injection of sperm cytosolic factor into mouse metaphase II oocytes induces different developmental fates according to the frequency of $\left[\mathrm{Ca}^{2+}\right]_{i}$ oscillations and oocyte age Biology of Reproduction 62 1370-1379

Gordo AC, Kurokawa M, Wu H and Fissore RA (2002b) Modifications of the $\mathrm{Ca}^{2+}$ release mechanisms of mouse eggs by fertilization and by the sperm factor Molecular Human Reproduction 8 619-629

Gordo AC, Rodrigues P, Kurokawa M, Jellerette T, Exley G, Warner C and Fissore RA (2002C) $\left[\mathrm{Ca}^{2+}\right]_{i}$ Oscillations signal apoptosis rather than activation in in vitro aged mouse eggs Biology of Reproduction $\mathbf{6 6}$ 1828-1837

Green DR and Reed JC (1998) Mitochondria and apoptosis Science $\mathbf{2 8 1}$ 1309-1312

Hawes SM, Chung YG and Latham KE (2001) Genetic and epigenetic factor affecting blastomere fragmentation in two-cell stage mouse embryos Biology of Reproduction 65 1050-1056

He CL, Damiani P, Parys JB and Fissore RA (1997) Calcium, calcium release receptors, and meiotic resumption in bovine oocytes Biology of Reproduction 57 1245-1255

Heiden MG and Thompson CB (1999) BCl-2 proteins: regulators of apoptosis or of mitochondrial homeostasis Nature Cell Biology $\mathbf{1}$ 209-216

Horiuchi T and Numabe T (1999) Intracytoplasmic sperm injection (ICSI) in cattle and other domestic animals: problems and improvement in practical use Journal of Mammalian Ova Research 16 1-9

Igarashi H, Takahashi E, Hiroi M and Doi K (1997) Aging-related changes in calcium oscillations in fertilized mouse oocytes Molecular Reproduction and Development 48 383-390

Jiang S, Chow SC, Nicotera P and Orrenius S (1994) Intracellular $\mathrm{Ca}^{2+}$ signals activate apoptosis in thymocytes: studies using the $\mathrm{Ca}^{2+}$-ATPase inhibitor thapsigargin Experimental Cell Research 212 84-92

Jones KT and Whittingham DG (1996) A comparison of sperm- and $\mathrm{IP}_{3^{-}}$ induced $\mathrm{Ca}^{2+}$ release in activated and aging oocytes Developmental Biology 178 229-237

Jones KT, Carroll J and Whittingham DG (1995) Ionomycin, thapsigargin, ryanodine, and sperm induced $\mathrm{Ca}^{2+}$ release during meiotic maturation of mouse oocytes Journal of Biological Chemistry 270 6671-6677

Juetten J and Bavister BD (1983) Effects of egg aging on in vitro fertilization and first cleavage division in the hamster Gamete Research 8 219-230

Jurisicova A, Latham KE, Casper RF and Varmuza SL (1998) Expression and regulation of genes associated with cell death during murine preimplantation embryo development Molecular Reproduction and Development 51 243-253

Kikuchi K, Naito K, Noguchi J, Shimada A, Kaneko H, Yamashita M, Aoki F, Tojo H and Toyoda Y (2000) Maturation/M-phase promoting factor: a regulator of aging in porcine oocytes Biology of Reproduction 63 $715-722$

Kimura Y, Yanagimachi R, Kuretake S, Bortkiewicz H, Perry ACF and Yanagimachi H (1998) Analysis of mouse oocyte activation suggests the involvement of sperm perinuclear material Biology of Reproduction $\mathbf{5 8}$ $1407-1415$
Kline D, Mehlmann L, Fox C and Terasaki M (1999) The cortical endoplasmic reticulum (ER) of the mouse egg: localization of ER clusters in relation to the generation of repetitive calcium waves Developmental Biology 215 431-442

Kono T, Carroll J, Swann K and Whittingham DG (1995) Nuclei from fertilized mouse embryos have $\mathrm{Ca}^{2+}$ releasing activity Development 121 $1123-1128$

Kume S, Yamamoto A, Inoue T, Muto A, Okano H and Mikoshiba K (1997) Developmental expression of the inositol 1,4,5-trisphosphate receptor in the endoplasmic reticulum during oogenesis and meiotic maturation of Xenopus laevis. Developmental Biology 182 228-239

Kuo TH, Kim HR, Zhu L, Yu Y, Lin HM and Tsang W (1998) Modulation of endoplasmic reticulum calcium pump by $\mathrm{Bcl}-2$ Oncogene 17 1903-1910

Liu L, Trimarchi JR and Keefe DL (2000) Involvement of mitochondria in oxidative stress-induced cell death in mouse zygotes Biology of Reproduction 62 1745-1753

Liu L, Hammar K, Smith PJS, Inoue S and Keefe DL (2001) Mitochondria modulation of calcium signaling at the initiation of development Cell Calcium 30 423-433

*Marston JH and Chang MC (1964) The fertilizable life of ova and their morphology following delayed insemination in mature and immature mice Journal of Experimental Zoology 155 237-252

Martinez F, Rienzi L, lacobelli M, Ubaldi F, Mendoza C, Greco E and Tesarik J (2002) Caspase activity in preimplantation human embryos is not associated with apoptosis Human Reproduction 17 1584-1590

Mehlmann LM and Kline D (1994) Regulation of intracellular calcium in the mouse egg: calcium release in response to sperm or inositol trisphosphate is enhanced after meiotic maturation Biology of Reproduction $\mathbf{5 1}$ 1088-1098

Mehlmann LM, Mikoshiba K and Kline D (1996) Redistribution and increase in cortical inositol 1,4,5-trisphosphate receptors after meiotic maturation of the mouse oocyte Developmental Biology 180 489-498

*Miyazaki S, Shirakawa H, Nakada K and Honda Y (1993) Essential role of the inositol 1,4,5 triphosphate receptor/ $\mathrm{Ca}^{2+}$ release channel in $\mathrm{Ca}^{2+}$ waves and $\mathrm{Ca}^{2+}$ oscillations at fertilization of mammalian eggs Developmental Biology 158 62-78

Morita Y and Tilly JL (1999) Oocyte apoptosis: like sand through an hourglass Developmental Biology 213 1-17

Morita Y, Perez GI, Maravei DV, Tilly KI and Tilly JL (1999) Targeted expression of $\mathrm{BCl}-2$ in mouse oocytes inhibits ovarian follicle atresia and prevents spontaneous and chemotherapy-induced oocyte apoptosis in vitro. Molecular Endocrinology 13 841-850

Nakano Y, Shirakawa H, Mitsuhashi N, Kuwabara Y and Miyazaki S (1997) Spatiotemporal dynamics of intracellular calcium in the mouse egg injected with spermatozoon Molecular Human Reproduction 3 1087-1093

Ogonuki, N, Sankai T, Yagami K, Shikano T, Oda S, Miyazaki S and Ogura A (2001) Activity of a sperm-borne oocyte-activating factor in spermatozoa and spermatogenic cells from cynomolgus monkeys and its location after oocyte activation Biology of Reproduction 65 351-357

Oltavai ZN, Milliman CL and Korsmeyer SJ (1993) BCl-2 heterodimerizes in vivo with a conserved homologue, Bax, that accelerates programmed cell death Cell 74 609-619

Patel S, Joseph SK and Thomas AP (1999) Molecular properties of inositol 1,4,5-trisphosphate receptors Cell Calcium 25 247-264

Perez GI, Knudson CM, Leykin L, Korsmeyer SJ and Tilly JL (1997) Apoptosis-associated signaling pathways are required for chemotherapy-mediated female germ cell destruction Nature Medicine 3 9893-9898

Perez GI, Tao XJ and Tilly JL (1999a) Fragmentation and death (a.k.a. apoptosis) of ovulated oocytes Molecular Human Reproduction 5 $414-420$

*Perez GI, Robles R, Knudson CM, Flaws JA, Korsmeyer SJ and Tilly JL (1999b) Prolongation of ovarian lifespan into advanced chronological age by Bax-deficiency Nature Genetics 21 200-203

Perez GI, Trobovich AM, Gosden RG and Tilly JL (2000) Mitochondria and the death of oocytes Nature 403 500-501

Perry ACF, Wakayama T and Yanagimachi R (1999) A novel transcomplementation assay suggests full mammalian oocyte activation is 
coordinately initiated by multiple, submembrane sperm compartments Biology of Reproduction 60 747-755

Perry ACF, Wakayama T, Cooke IM and Yanagimachi R (2000) Mammalian oocyte activation by the synergistic action of discrete sperm head components: induction of calcium transients and involvement of proteolysis Developmental Biology 217 386-393

Pinton P, Ferrari D, Magalhaes P, Schulze-Osthoff K, Di Virgilio F, Pozzan T and Rizzuto R (2000) Reduced loading of intracellular $\mathrm{Ca}^{2+}$ stores and downregulation of capacitative $\mathrm{Ca}^{2+}$ influx in $\mathrm{Bcl}$-2-overexpressing cells Journal of Cell Biology 148 857-862

Rucker EB, Dierisseau P, Wagner KU, Garrett L, Wynshaw-Boris A, Flaws JA and Hennighausen $\mathbf{L}$ (2000) BCl-x and Bax regulate mouse primordial germ cell survival and apoptosis during embryogenesis Molecular Endocrinology 7 1038-1052

Schultz RM and Kopf GS (1995) Molecular basis of mammalian egg activation Current Topics in Developmental Biology 30 21-62

Shiraishi K, Okada A, Shirakawa H, Nakanishi S, Mikoshiba K and Miyazaki S (1995) Developmental changes in the distribution of the endoplasmic reticulum and inositol 1,4,5-trisphosphate receptors and the spatial pattern of $\mathrm{Ca}^{2+}$ release during maturation of hamster oocytes Developmental Biology 170 594-606

Smith JJ, Evans EK, Murakami M, Moyer MB, Moseley MA, Vande Woude G and Kornbluth S (2000) Wee1-regulated apoptosis mediated by the Crk adaptor protein in Xenopus egg extracts Journal of Cell Biology 151 1391-1400

Soboloff J and Berger SA (2002) Sustained ER Ca ${ }^{2+}$ depletion suppresses protein synthesis and induces activation-enhanced cell death in mast cells Journal of Biological Chemistry 277 13 812-13820

Souza M, Barros A, Silva J and Tesarik J (1997) Developmental changes in calcium content of ultrastructurally distinct subcellular compartments of preimplantation human embryos Molecular Human Reproduction 3 83-90

Stricker SA (1999) Comparative biology of calcium signaling during fertilization and egg activation in animals Developmental Biology 211 157-176

Suttner R, Zakhartchenko V, Stojkovic P, Muller S, Alberio R, Medjugorac I, Brem G, Wolf E and Stojkovic M (2000) Intracytoplasmic sperm injection in bovine: effects of oocyte activation, sperm pretreatment, and injection technique Theriogenology 54 935-948

*Swann K and Lai FA (1997) A novel signaling mechanism for generating $\mathrm{Ca}^{2+}$ oscillations at fertilization in mammals Bioessays 19 371-378

Swann K, Parrington J and Jones KT (2001) Potential role of a sperm-derived phospholipase $\mathrm{C}$ in triggering the egg-activating $\mathrm{Ca}^{2+}$ signal at fertilization Reproduction 122 839-846

*Szalai G, Krishnamurthy R and Hajnóczky G (1999) Apoptosis driven by $\mathrm{IP}_{3}$-linked mitochondrial calcium signals EMBO Journal 18 6349-6361

Takahashi T, Saito H, Hiroi M, Doi K and Takahashi E (2000) Effects of aging on inositol 1,4,5-triphosphate-induced $\mathrm{Ca}^{2+}$ release in unfertilized mouse oocytes Molecular Reproduction and Development 55 299-306

Takase K, Ishikawa M and Hoshiai H (1995) Apoptosis in the degeneration process of unfertilized mouse ova Tohoku Journal of Experimental Medicine 175 69-76

Tarin JJ, Ten J, Vendrell FJ and Cano A (1998) Dithiothreitol prevents ageassociated decrease in oocyte/conceptus viability in vitro. Human Reproduction 13 381-386
Tarin JJ, Albalá-Pérez S, Aguilar A, Minarro J, Hermenegildo C and Cano C (1999) Long-term effects of postovulatory aging of mouse oocytes on offspring: a two-generational study Biology of Reproduction 61 1347-1355

Tarin J, Perez-Albala S and Cano A (2001) Cellular and morphological traits of oocytes retrieved from aging mice after exogenous ovarian stimulation Biology of Reproduction 65 141-150

Tesarik J, Sousa M and Testart J (1994) Human oocyte activation after intracytoplasmic sperm injection Human Reproduction 9 511-518

Thornberry NA and Lazebnik Y (1998) Caspases: enemies within Science 281 1312-1316

Tilly Jl (2001) Commuting the death sentence: how oocytes strive to survive Nature Reviews Molecular Cellular Biology 2 838-848

Trump BF and Berezesky IK (1995) Calcium-mediated cell injury and cell death FASEB Journal 9 219-228

Van Blerkom J, Davis PW and Lee J (1995) ATP content of human oocytes and the developmental potential and outcome after in-vitro fertilization and embryo transfer Human Reproduction 10 415-424

Wada M, Hosotani R, Lee JU et al. (1998) An exogenous cdk inhibitor, butyrolactone-I, induces apoptosis with increased $\mathrm{Bax} / \mathrm{BCl}-2$ ratio in p53-mutated pancreatic cancer cells Anticancer Research $\mathbf{1 8}$ 2559-2566

Wang H-G, Pathan N, Ethel IM, Krajewski S, Yamaguchi Y, Shibasaki F, McKeon F, Bobo T, Franke TF and Reed JC (1999) $\mathrm{Ca}^{2+}$-induced apoptosis through calcineurin dephosphorylation of Bad Science $\mathbf{2 8 4}$ $339-343$

Wang X (2001) The expanding role of the mitochondria in apoptosis Genes and Development 15 2922-2933

Warner CM, Cao W, Exley GE, McElhinny AS, Alikani M, Cohen J, Schott RT and Brenner CA (1998) Genetic regulation of egg and embryo survival Human Reproduction 13 178-190

Wassarman PM and Albertini DF (1994) The mammalian ovum. In The Physiology of Reproduction Vol. 1 2nd Edn pp 79-122 Eds E Knobil and JD Neil. Raven Press, New York

Webb M, Howlett SK and Maro B (1986) Parthenogenesis and cytoskeletal organization in aging mouse eggs Journal of Embryology and Experimental Morphology 95 131-145

Weil M, Jacobson MD, Coles HS, Davies TJ, Gardner RL, Raff KD and Raff MC (1996) Constitutive expression of the machinery for programmed cell death Journal of Cell Biology 133 1053-1059

Wilding M, Dale B, Marino $M$, di Mateo L, Alviggi C, Pissature ML, Lombardi L and De Placido G (2001) Mitochondrial aggregation patterns and activity in human oocytes and preimplantation embryos Human Reproduction 16 909-917

Wu H, He CL and Fissore RA (1997) Injection of a porcine sperm factor triggers calcium oscillations in mouse oocytes and bovine eggs Molecular Reproduction and Development 46 176-189

Xu Z, Abbott A, Kopf GS, Schultz RM and Ducibella T (1997) Spontaneous activation of ovulated mouse eggs: time-dependent effects on M-phase exit, cortical granule exocytosis, maternal messenger ribonucleic acid recruitment, and inositol 1,4,5-trisphosphate sensitivity Biology of Reproduction 57 743-750

Zha J, Harada H, Yang E, Jockel J and Kornsmeyer SJ (1996) Serine phosphorylation of death agonist bad in response to survival factor results in binding to 14-3-3 not BCL-XI Cel/ 87 619-628 